\title{
High Pressure Water-Jet Technology for the Surface Treatment of Al-Si Alloys and Repercussion on Tribological Properties
}

\author{
Md. Aminul Islam ${ }^{1 *}$, Zoheir Farhat $^{1}$, Jonathon Bonnell ${ }^{2}$ \\ ${ }^{1}$ Department of Process Engineering and Applied Science, Dalhousie University, Halifax, Canada; ${ }^{2}$ Vector Aerospace, Engine Ser- \\ vices-Atlantic, Summerside, Canada. \\ Email: *Md.Aminul.Islam@Dal.Ca, Zoheir.Farhat@Dal.Ca
}

Received June 27 $7^{\text {th }}$ 2011; revised August $3^{\text {rd }}, 2011$; accepted August $16^{\text {th }}, 2011$.

\begin{abstract}
Recent developments in high pressure water-jet technology have brought the process to the forefront as a means of surface treatment. Water jet technology offers cleaning, cutting, processing as well as potential refinement of surface properties. By adapting the process parameters the surface characteristics can be changed while the profile remains the same. In the present study, water-jet technology was used for the surface treatment of Al-Si alloy to investigate its effect on tribological properties. Dry sliding wear behavior was investigated against AISI 52100 bearing steel ball using a reciprocating ball-on-flat configuration. Optical microscopy examination reveals that ploughing of grains, transgranular and intergranular propagation of cracks; are the mechanisms by which material is removed during water jet treatment. While, on the other hand, SEM observation of the wear track reveals that plastic deformation and delamination are the dominant wear mechanism during the wear process. Water jet treatment was compared to hot isostatic pressing in terms of its effects on wear resistance and surface porosity of Al-Si alloy. It was found that, hot isostatic pressing reduces the total amount of porosity at the expanse of hardness while water jet treatment produces a compressed surface having higher hardness and compressive residual stress, which ultimately increases wear resistance.
\end{abstract}

Keywords: Tribology, High Pressure Water Jet Treatment, Porosity, Surface Treatment, XRD, Reciprocating Wear

\section{Introduction}

In recent years, the use of high-pressure water jet technique became widely accepted practice in order to meet the requirements of production and maintenance. Water-jet technologies offer cleaning, machining, surface treatment and cutting of materials. Both roughening as well as polishing is possible with this procedure. It is therefore excellent for pre-treatment of engineering surfaces. For the last few decades, water-jet technology covered the following applications: removal of paint, grease, dirt from aircraft in the aviation industry; prevent pump cavitation; removal of cement lips, incrustations, lime, solidified dust from autoclave vessel; removal of worn protective coating, incrustations, solidified materials in the chemical industry; semiconductor frame cleaning in the electronic industry; removal of weld slag, water scale, mill scale and rust in steel mills; water jet cutting; vibration free demolition by abrasive water jets and so on [1-11].

The conventional water jet technique has been used for cutting and polishing by mixing abrasive materials into the water which transport the abrasive materials to strike the substrate. On the other hand, high pressure water jet can produce a compressed surface layer without abrasive materials, while the core of the component remains unchanged. The new surface layer 'tribolayer' is expected to have enhanced tribological properties due to possible work hardening, residual stress and reduction of surface porosity. Hence, water jet treatment may be an effective technique for improved surface properties.

Aluminum-silicon based alloys have received considerable attention due to their high strength to weight ratio. The reduction in weight of components leads to significant impact on fuel economy in dynamic systems. In addition, these alloys are reported to have a reasonably high wear resistance. The wear resistance of Al-Si alloys depends on a number of material related parameters, i.e., size, shape, composition and distribution of micro-constituents, in addition to service conditions [12-16]. Porosity is a common feature of sintered Al-Si alloys and 
strongly influences their properties and applications. In general the presence of pores is accompanied by a drop in strength, ductility and wear resistance of materials [17]. Not only the total volume percentage of porosity influences the degradation of properties but also size, shape and interconnectivity of pores play an important role [18-20]. Meanwhile, initial attempts on the mechanical characterization of these materials were focused on static tests. However, in order to employ these materials in new applications, their dynamic properties have to be carefully assessed. In recent years, fatigue behavior has been studied in numerous investigations. The influence of pores on crack initiation and propagation under cyclic loading was examined as well [21,22]. The effect of water jet peening toward improving fatigue resistance was examined by various experimental tests and proved as an effective techniques for preventing fatigue in structural components [23-25].

The objective of this study is to assess the potential of employing high pressure water-jet technology for the surface treatment of Al-Si alloys to improve wear resistance for automobile and aerospace applications.

\section{Experimental Details}

In order to obtain a homogeneous distribution of porosity, samples were prepared using powder metallurgy method. Two powders (i.e., Al-Si master alloy and $\mathrm{Al}-\mathrm{Mg}$ master alloy), were mixed to produce the following alloy composition; $88.8 \mathrm{wt} \% \mathrm{Al}, 6.0 \mathrm{wt} \% \mathrm{Si}, 4.5 \mathrm{wt} \% \mathrm{Cu}, 0.5 \mathrm{wt} \%$ $\mathrm{Zn}, 0.2 \mathrm{wt} \% \mathrm{Fe}$. A Lico wax C was used as a pressing lubricant. Specimens were pressed at 100, 200 and 600 $\mathrm{MPa}$ and were sintered in a tube furnace in the presence of nitrogen gas at $5600 \mathrm{C}$ for 20 minutes and then slow cool to $4800 \mathrm{C}$. The green and sintered densities of samples were determined in accordance with MPIF Standard 42 [26] and are listed in Table 1. For micro-structural experiments, specimens were cut, mounted and ground using 240, 320, 400 and 600 grit $\mathrm{SiC}$ abrasive papers and then polished using $1 \mu \mathrm{m}, 0.3 \mu \mathrm{m}$ and $0.05 \mu \mathrm{m}$ gama alumina suspension. Olympus BX51 research microscope, equipped with bright-field objectives was used to analyze the microstructure at high resolution.
Table 1. Basic properties of sintered Al - 6 wt\% Si alloy.

\begin{tabular}{ccc} 
Specimens & $\begin{array}{c}\text { Green Density } \\
(\mathrm{g} / \mathrm{cc})\end{array}$ & $\begin{array}{c}\text { Sintered Density } \\
(\mathrm{g} / \mathrm{cc})\end{array}$ \\
\hline $\begin{array}{c}\text { Pressed at } 100 \\
\mathrm{MPa}\end{array}$ & 2.11 & 2.33 \\
$\begin{array}{c}\text { Pressed at } 200 \\
\mathrm{MPa}\end{array}$ & 2.29 & 2.46 \\
$\begin{array}{c}\text { Pressed at } 600 \\
\mathrm{MPa}\end{array}$ & 2.58 & 2.6 \\
\hline
\end{tabular}

Water-jet treatment was performed using a highly pressurized water-jet. The system is capable of employing ultrasonic pulses of water-jet for more intense treatment. Several tests were performed using the ultrasonic system. During experiments, specimens were individually mounted on a turntable inside the water jet enclosure. Specimens containing different amount of porosity (compacted at 100, 200 and $600 \mathrm{MPa}$ ) were subjected to water jet at four different pressures, 34, 48, 55 and $70 \mathrm{MPa}$, employing a nozzle with an orifice size of $1.6 \mathrm{~mm}$. The standoff distances between the nozzle and the specimen were $25,64,76 \mathrm{~mm}$ and the translation speeds were 25 , 50,150 and $250 \mathrm{~mm} / \mathrm{s}$.

Surface porosities of samples were calculated using image analysis software. A series of images were taken to cover the whole surface area of the sample. Porosities were identified based on their gray-level intensity differences compared to the matrix. Gray-level threshold settings were selected to permit independent detection of porosity, using the 'flicker method' of switching back and forth between porosity and the matrix. Second phase particles and dendrite, may be counted as porosity because their gray level range is similar to that of porosity. The grey-level thresholds as well as boundary conditions, (i.e., aspect ratio, min radius and area) were set to avoid second phase particles and dendrite. A counting protocol was chosen to correct for edge effects so that a porosity lying across a field boundary is counted only once [27]. For each field the area fraction of the detected area of porosity was measured by dividing the detected area of porosity by the area of the measurement field. Surface porosity values are given in Table 2.

Table 2. Surface porosity of sintered Al - Si alloy.

\begin{tabular}{cccccccc}
\hline & \multicolumn{2}{c}{ Untreated } & \multicolumn{2}{c}{ After HIP } & \multicolumn{3}{c}{ After water jet } \\
\cline { 2 - 8 } Specimens & $\begin{array}{c}\text { \% Surface } \\
\text { Porosity }\end{array}$ & $\begin{array}{c}\text { Average Pore Size } \\
(\mu \mathrm{m})\end{array}$ & $\begin{array}{c}\text { \%Surface Po- } \\
\text { rosity }\end{array}$ & $\begin{array}{c}\text { Average Pore Size } \\
(\mu \mathrm{m})\end{array}$ & $\begin{array}{c}\text { \% Surface } \\
\text { Porosity }\end{array}$ & $\begin{array}{c}\text { \% Sub surface } \\
\text { Porosity }\end{array}$ & $\begin{array}{c}\text { Average Pore Size } \\
(\mu \mathrm{m})\end{array}$ \\
\hline $\begin{array}{c}\text { Pressed at 100 } \\
\text { MPa }\end{array}$ & $6.71 \pm 0.01$ & 82.4 & $2.13 \pm 0.01$ & 34.6 & $9.14 \pm 0.01$ & $5.33 \pm 0.01$ & 86.5 \\
$\begin{array}{c}\text { Pressed at 200 } \\
\text { MPa }\end{array}$ & $4.22 \pm 0.01$ & 70.2 & $1.34 \pm 0.01$ & 23.5 & $4.37 \pm 0.01$ & $3.65 \pm 0.01$ & 73.2 \\
$\begin{array}{c}\text { Pressed at 600 } \\
\text { MPa }\end{array}$ & $2.35 \pm 0.01$ & 46.9 & $0.75 \pm 0.01$ & 20.4 & $3.80 \pm 0.01$ & $1.97 \pm 0.01$ & 48.8 \\
\hline
\end{tabular}


Micromet micro-hardness tester was used to measure the micro-hardness of the specimens. This was conducted to assess the effect of water jet treatment on the sub-surface properties of the Al-Si alloy. In this test method, Vickers hardness measurements were performed using a diamond indenter and $15 \mathrm{~g}$ load. The size of the indentation was measured using a light microscope equipped with a filar type eyepiece. HV measurements were taken as a function of depth from the treated surface.

In order to measure residual stresses induced as a result of the high pressure water jet treatment, X-ray peak broadening diffraction techniques was employed. X-ray diffraction (XRD) experiment was carried out on a specimen treated ultrasonically at $48 \mathrm{MPa}$ from $76 \mathrm{~mm}$ standoff distance and $150 \mathrm{~mm} / \mathrm{s}$ translation speed, employing a high-speed Bruker D8 Advance system using $\mathrm{Cu}-\mathrm{K} \alpha$ radiation having a wave length $(\lambda)$ of $1.54 \AA$, tube voltage of $40 \mathrm{KV}$, and tube current of $40 \mathrm{~mA}$. The strongest four peaks (i.e., (111), (200), (220) and (311)) were selected for slow scan of $0.02 \%$ sec. The integral breadth of XRD peaks were analysed using EVA software package. Peaks were corrected for the effects of $\mathrm{K} \alpha 2$ radiation and the background was removed. A standard stress-free Al from the same alloy was used to measure instrumental broadening. The data was treated according to Williamson-Hall method [28]. The integral breadth (i.e., total area under the peak/peak height) of the diffraction peak can be expressed as,

$$
\mathrm{B}_{\text {obs }}=\mathrm{B}_{\text {ins }}+\mathrm{B}_{\text {size }}+\mathrm{B}_{\varepsilon}
$$

Here $\mathrm{B}_{\text {size }}$ and $\mathrm{B}_{\varepsilon}$ are the grain size and micro-strain contributions to the observed peak broadening $\mathrm{B}_{\text {obs }}$ respectively. $B_{\text {ins }}$ is the peak broadening at a stress-free state, referring to the instrument contribution. The crystalline size ' $t$ ' is related to $B_{\text {size }}$ by the Scherrer equation [29],

$$
\mathrm{t}=\frac{0.9 \lambda}{\mathrm{B}_{\text {size }} \cos \theta_{B}}
$$

Here, $\theta_{B}$ is Bragg's angle. While the micro-strain can be calculated from,

$$
\mathrm{B}_{\varepsilon}=2\left(\frac{\Delta \mathrm{d}}{\mathrm{d}}\right) \tan \theta_{B}
$$

Where, $d$ is the interplaner spacing. Substituting equation (2) and (3) into (1) gives,

$$
\left(\mathrm{B}_{\text {obs }}-\mathrm{B}_{\text {ins }}\right) \cos \theta_{B}=\frac{0.9 \lambda}{\mathrm{t}}+2\left(\frac{\Delta \mathrm{d}}{\mathrm{d}}\right) \sin \theta_{B}
$$

For grain size larger than $10 \mu \mathrm{m}$ (as in the present case) $\mathrm{X}$-ray peak broadening is due to micro-strain effect alone, hence, the first term in equation (4) can be eliminated.
Dry reciprocating wear tests were performed using a Universal Micro-Tribometer. This test method utilizes a ball upper specimen that slides against a flat lower specimen in a linear, back and forth, sliding motion having a stroke length of $5.03 \mathrm{~mm}$. All tests were conducted at room temperature and a relative humidity of $40-55 \%$. The load is applied downward through the ball specimen against the flat specimen mounted on a reciprocating drive. The tester allows for monitoring the dynamic normal load, friction force and depth of the wear track during the test. A $6.3 \mathrm{~mm}$ diameter AISI 52100 bearing steel ball having a hardness of HRA 83 was used as a counterface material. The ball was mounted inside a ball holder which was attached directly to a suspension system, which, in turn, is attached to a load sensor that controls and records forces during the test. The weight of the specimen was measured before and after each wear test to determine individual weight loss at selected time intervals. $10 \mathrm{~N}$ normal load and $15 \mathrm{~Hz}$ frequency were employed for three different time intervals (10 min, $45 \mathrm{~min}$ and $90 \mathrm{~min}$ ). After wear tests, worn surfaces and cross section of the wear track were examined using optical and scanning electron microscopy to determine possible wear mechanisms.

\section{Results and Discussion}

The size, shape and amount of pores are largely dependent on processing parameters. As all the specimens were sintered under the same sintering conditions, the compaction pressure plays the most significant role in determining pore size, shape and amount. Increasing the compaction pressure decreases the amount of porosity and reduces pore size, while the pore shape changes from large irregular to small round shape. The percent surface porosity ranges from $6.71 \%$ to $2.35 \%$, while the average pore size ranges from $82.4 \mu \mathrm{m}$ to $46.9 \mu \mathrm{m}$ respectively as the compaction pressure of the Al-Si alloy powder is raised (Table 2). The low standard deviations of surface porosities indicate a uniform distribution of porosity throughout the structures. To mitigate the detrimental effect of porosity, specimens were subjected to hot isostatic pressing (HIP) treatment. HIP gave rise to a decrease of approximately $68 \%$ in surface porosity and $60 \%$ in pore size. On the other hand, when the sintered Al-Si alloy was subjected to high pressure water-jet (using $70 \mathrm{MPa}$ pressure, $64 \mathrm{~mm}$ distance and $25 \mathrm{~mm} / \mathrm{s}$ ) it is found that there is an increase of $36 \%, 4 \%$ and $61 \%$ in surface porosity at compact pressure of 100, 200 and 600 $\mathrm{MPa}$, respectively. Moreover, there is approximately $4.3 \%$ increase in the average pore size after water jet treatment. While there is around $16 \%$ reduction in porosity in the subsurface region ( $22 \pm 3 \mu \mathrm{m}$ from the surface) 
after the water jet treatment. It has also found that treated surfaces exhibit high roughness. The discrepancy in the amount of porosities and size of pores between the surface and near surface (Table 2) is attributed to the difficulty of measuring surface porosity when surface roughness is high. Therefore, near surface porosity is a better indicator of the amount and size of porosity.

In the water jet process, jet pressure, standoff distance and translation speed have a significant impact on final surface properties.

During the water jet treatment, water jet strikes the surface at a relatively high velocity which causes a significant amount of material loss. The amount of material loss increases with water jet pressure. Figure 1 shows a representative image showing the surface damage after water jet treatment. In this particular situation, the specimen compacted at $100 \mathrm{MPa}$ was subjected to 55 $\mathrm{MPa}$ jet pressure operated from $25 \mathrm{~mm}$ standoff distance at $50 \mathrm{~mm} / \mathrm{s}$ translation speed reveal a depth of the material removal of about $900 \mu \mathrm{m}$. The insert on the upper right corner of the image (Figure 1) shows the position where the depth measurement was taken.

Optical microscopy examination reveals that ploughing of grains, transgranular, intergranular propagation of cracks and as a consequence, break away and pulling out of grains are the mechanisms for material removal during water jet treatment. Figure 2(a)-(e) shows a cross-section of a specimen compacted at $600 \mathrm{MPa}$ and treated ultrasonically at $34 \mathrm{MPa}$ at a translation speed of 250 $\mathrm{mm} / \mathrm{s}$ and standoff distance of $64 \mathrm{~mm}$. In Figure 2(a), shows transgranular crack propagating through a grain, while Figure 2(b) reveals a portion of a grain breaking away. It was also observed that the water jet penetrates along the grain boundaries promoting intergranular cracks to develop (Figure 2(c)). This leads to pulling out of grains as shown in Figure 2(d). Figure 2(e) shows ploughing of grains along the water jet path. SEM observation

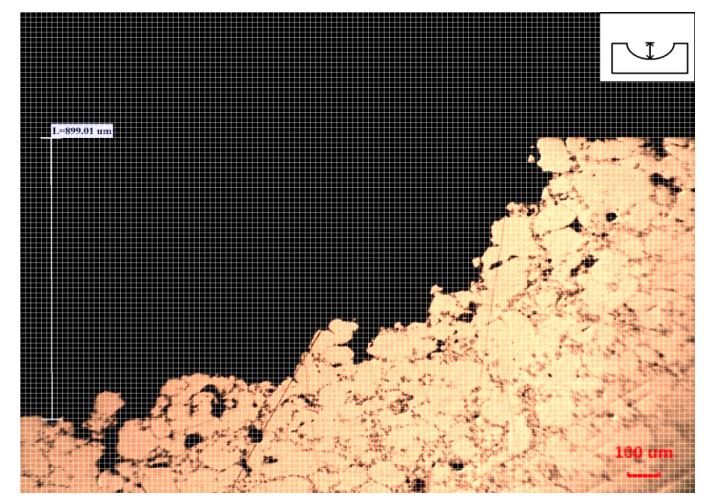

Figure 1. Surface damage due to $55 \mathrm{MPa}$ water jet pressure, $25 \mathrm{~mm}$ standoff distance and $50 \mathrm{~mm} / \mathrm{s}$ translation speed. of the surface on the other hand, reveal that water jet pressure causes collapse of porosity underneath the surface. Figure 2(f) shows an SEM image of the specimen compacted at $100 \mathrm{MPa}$ and treated ultrasonically at 48 $\mathrm{MPa}$ from $76 \mathrm{~mm}$ standoff distance and at $150 \mathrm{~mm} / \mathrm{s}$ translation speed. It is observed from the figure what appears to be a sub-surface porosity collapse due to the pressure created by the water jet, hence, producing low porosity subsurface 'tribolayer'.

In order to investigate the effect of water-jet treatment on hardness, a series of micro-hardness measurements were conducted according to ASTM standard [30]. Hardness was measured at three different depths, $17 \pm 3$, $122 \pm 5$ and $1000 \pm 5 \mu \mathrm{m}$ below the treated surface. Figure 3 shows the variation of hardness at different distance below the surface of the specimen compacted at $100 \mathrm{MPa}$ and treated at $55 \mathrm{MPa}$ water jet pressure from $25 \mathrm{~mm}$ standoff distance at $50 \mathrm{~mm} / \mathrm{s}$ translation speed. Each hardness value in the figure represent an average of 10 measurements. It is evident from the figure that the hardness drops gradually away from the treated surface.

There is about $15 \%$ increase in hardness in the vicinity of the surface as compared to hardness of the base metal about $1 \mathrm{~mm}$ from the surface. It is believed that the observed rise in hardness closer to the surface is due to work hardening effects as a result of the high pressure water jet treatment.

Figure 4 shows the superimposed XRD diffraction peaks of the standard and water jet treated specimens as representative peaks. It should be noted that neither broadening nor sifting of peaks was observed for the untreated sample. XRD of the all scanned peaks were only slightly broadened but significantly shifted to the right after water jet treatment. According to peak broadening calculations the microstrain of the treated specimen was found to be $10 \times 10^{-5}$. It can be shown that the residual stress resulting from microstraiin analysis is $7 \mathrm{MPa}$ (i.e., $\sigma_{\text {res }}=\varepsilon E$, where, $\mathrm{E}=70 \mathrm{GPa}$ [31]). On the other hand, the macrostrain (uniform strain) calculated from the shifts in peak positions, as $(\Delta \mathrm{d} / \mathrm{d})$, is $6 \times 10^{-4}$ and the residual stress was calculated to be $42 \mathrm{MPa}$. The measured macrostrain and, hence, the associated residual stress are compressive as peak shifts are to the right (toward higher Bragg angle). As in the XRD diffraction method, only planes parallel to the surface contribute to the measured intensity, crystal planes parallel to the surface are under compression due to the water jet treatment. The measured compressive residual stress promotes the closing of surface and near surface pores, hence, raising the hardness in the 'tribolayer' and retarding crack initiation and propagation during wear.

In order to investigate wear performance of the sintered 


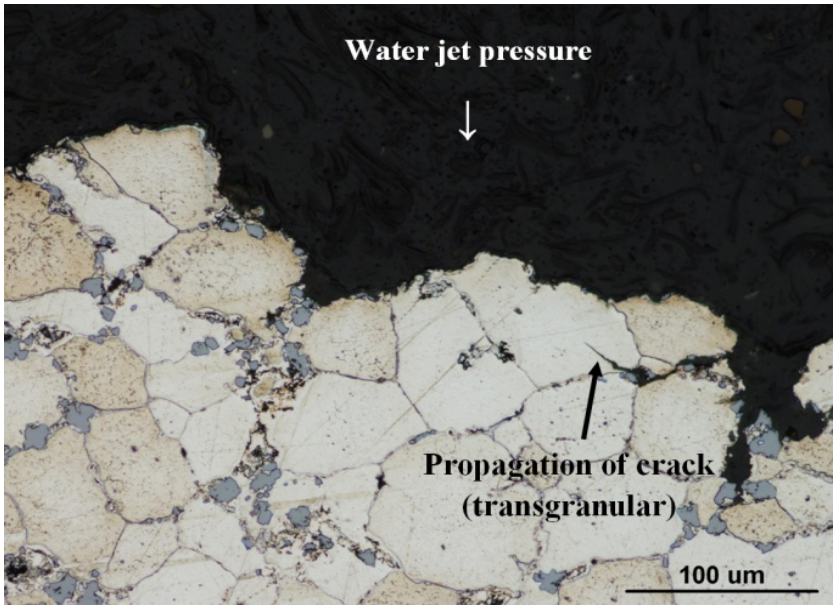

(a)

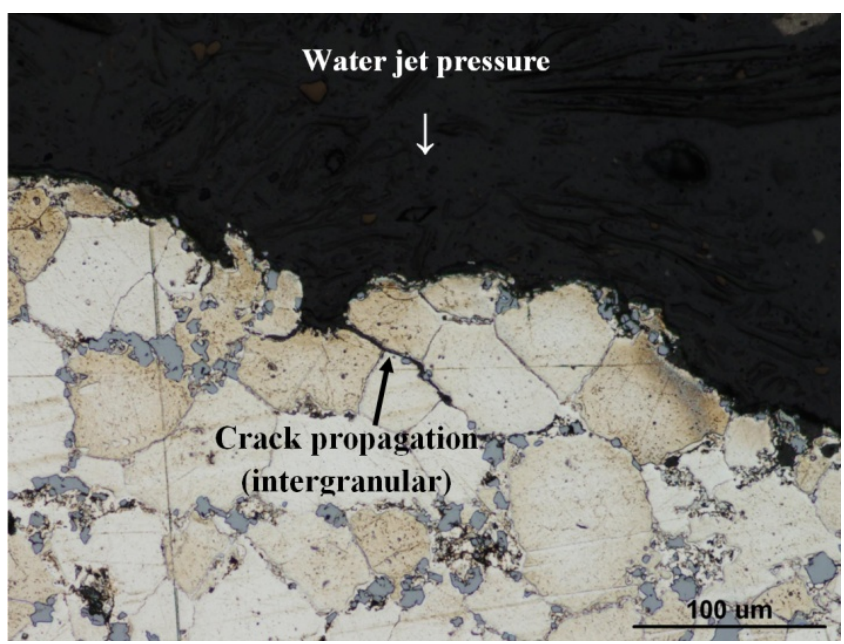

(c)

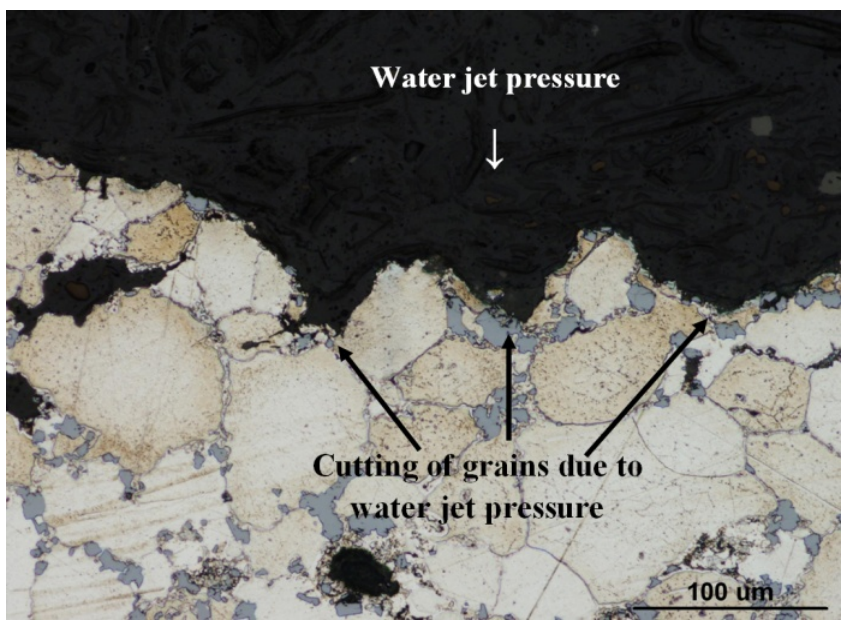

(e)

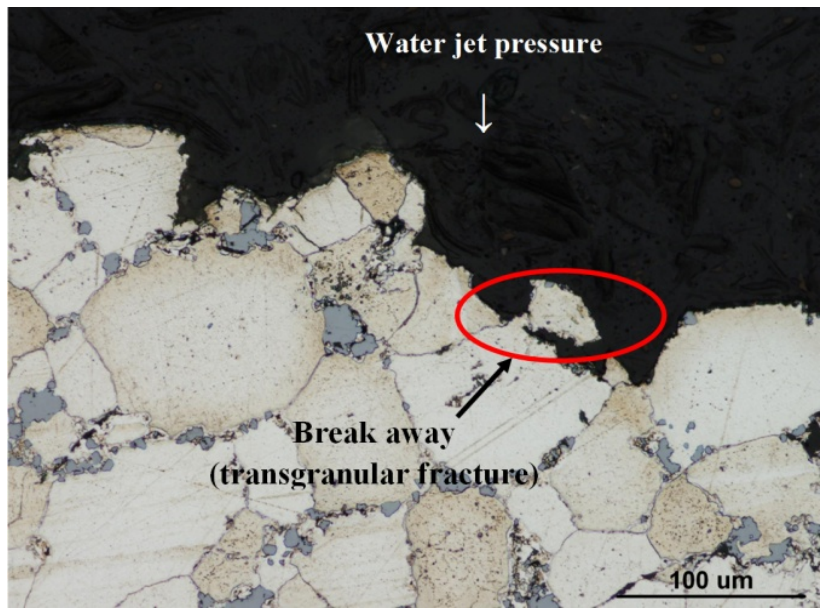

(b)

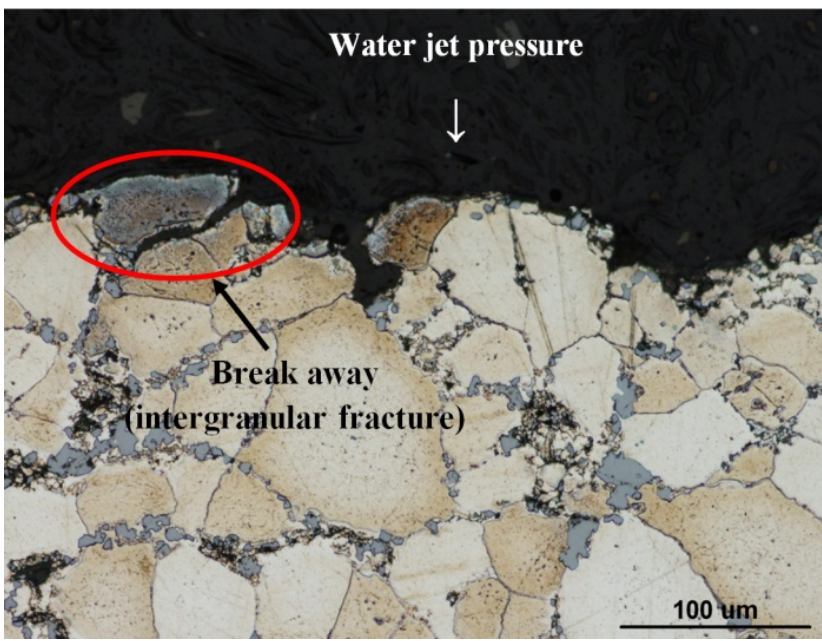

(d)

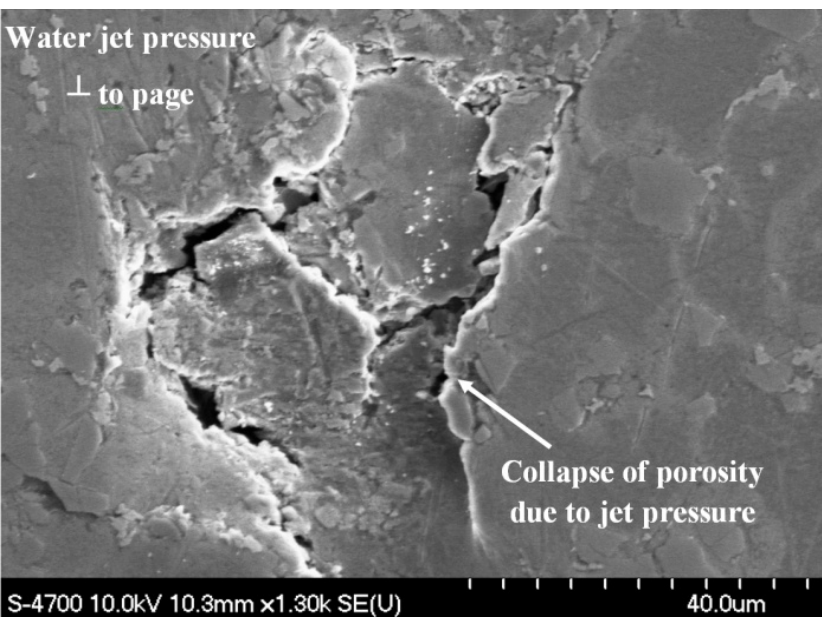

(f)

Figure 2. X-section of a specimen compacted at $600 \mathrm{MPa}$, (a) transgranular crack propagation; (b) break away of grains; (c) intergranular crack propagation, (d) pulling out of grains, (e) ploughing of grains, (f) collapse of porosity due to water jet pressure. 


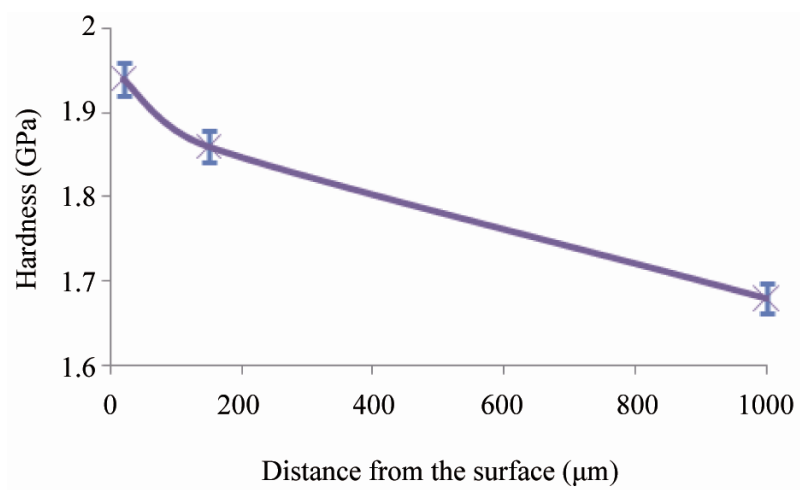

Figure 3. Variation of hardness at different depth below the surface.

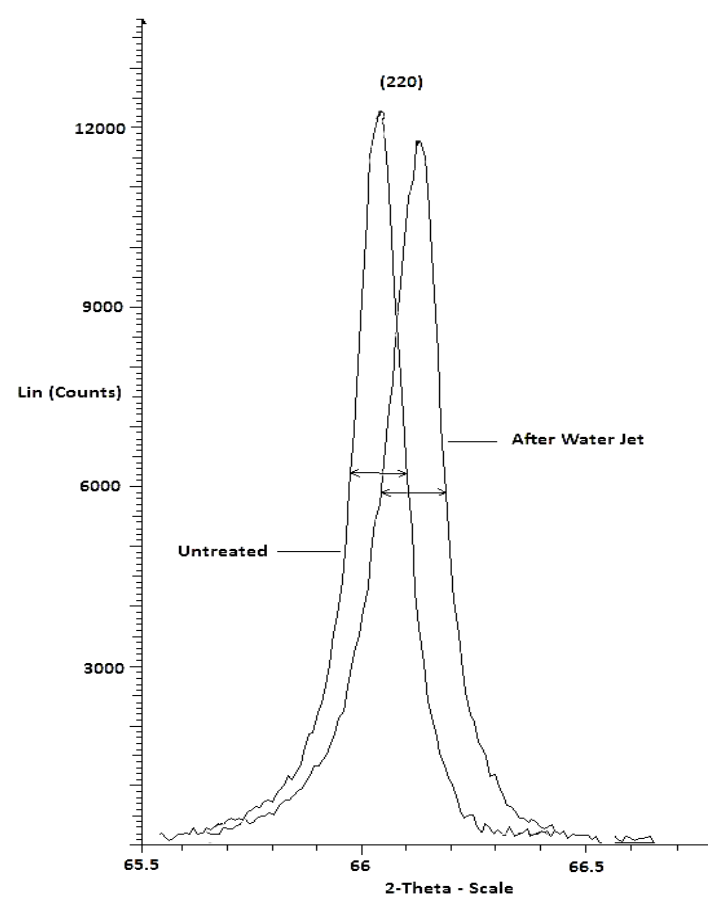

Figure 4. (220) X-ray diffraction peak of water jet treated and standard Al specimens.

Al-Si alloy after water jet treatment and compare to untreated and HIPed conditions, reciprocating wear tests were performed under $10 \mathrm{~N}$ normal load and $15 \mathrm{~Hz}$ frequency at three time intervals $(10 \mathrm{~min}, 45 \mathrm{~min}$ and 90 $\mathrm{min})$. For the water-jet treated specimens, the operating condition are as follows: $70 \mathrm{MPa}$ from $64 \mathrm{~mm}$ standoff distance and $25 \mathrm{~mm} / \mathrm{s}$ translation speed. Figure 5 depicts the data collected during wear tests. The figure shows a somewhat linear increase (with no transition) in weight loss with sliding distance. The fact that there are no wear transitions may indicate that the same wear mechanism(s) is operative throughout the duration of the tests. As we observed from the figure, $100 \mathrm{MPa}$ specimens (under all conditions) exhibit higher weight loss compared to 600 MPa specimens (under corresponding conditions) due to lower porosity content in the specimens. On the other hand, for any given compaction pressure (i.e., percent porosity), water jet treated specimens exhibit lower weight loss compared to HIPed and untreated specimens.

Wear rates (i.e., slope of best fit weight loss versus sliding distance lines) are calculated from Figure 5 and their variation under various compaction pressures are plotted in Figure 6. It is clear that the specimens subjected to water jet treatment exhibit superior wear resistance compared to both untreated and HIPed specimens. For the specimens compacted at 100, 200 and $600 \mathrm{MPa}$, wear resistance increases by $4.3,3.8$ and $14.7 \%$ respectively after HIP, while after water jet treatment, there is $34.7,36.4$ and $57.3 \%$ increase in wear resistance, respectively.

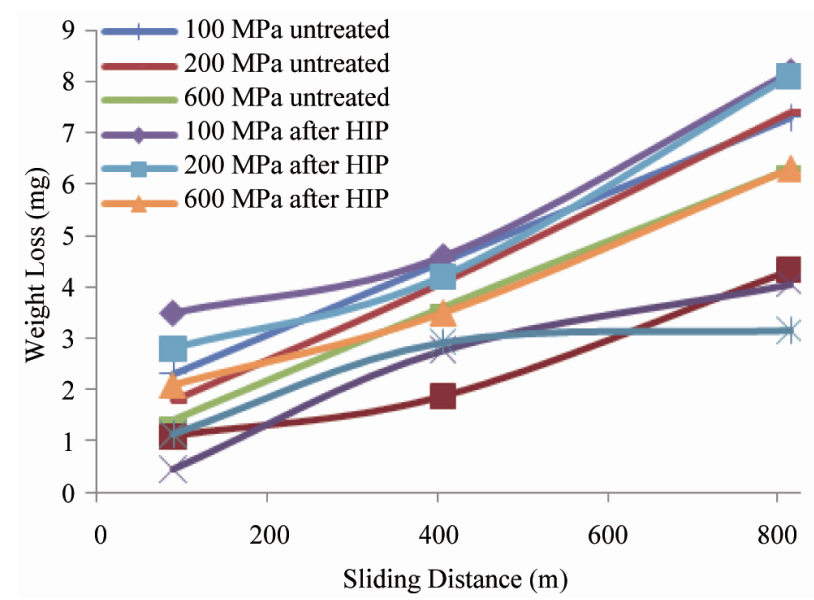

Figure 5. Weight loss vs sliding distance.

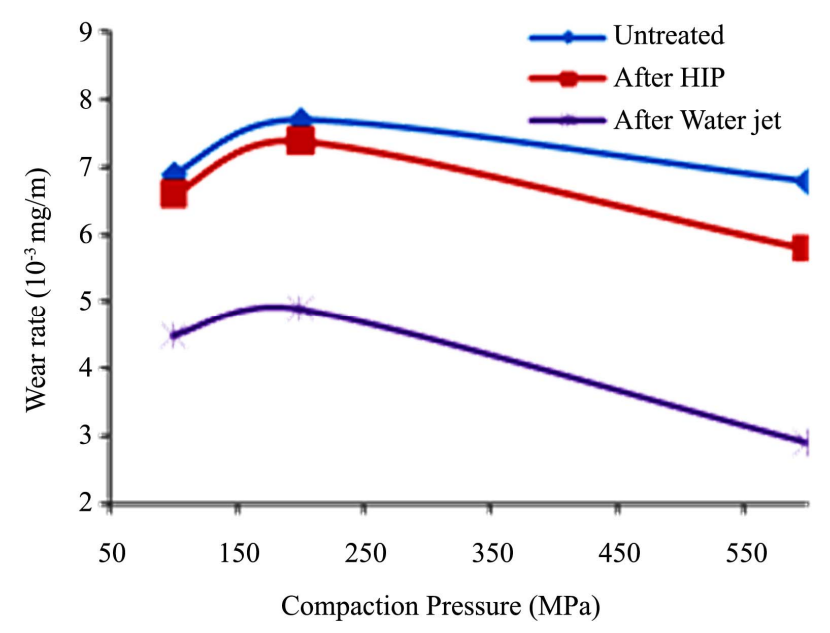

Figure 6. Wear rate at different operating condition. 
The improvement in wear resistance of water jet treated specimens as opposed to hipped and untreated specimen can be explained in terms of variation in porosity and hardness levels post treatments. In the HIPed specimens, simultaneous application of heat and pressure reduces near surface internal voids and micro-porosity through a combination of plastic deformation, creep, and diffusion bonding. However, it has been found that, the final structure exhibit lower hardness due to softening at higher temperature due to HIP [34]. Water jet treatment was found to produce a compress layer and simultaneously increases hardness of the material.

To explain the initial increase and subsequent drop in wear rate with compaction pressure, detailed examination of the effect of porosity on wear mechanism is necessary. Scanning electron microscopy examinations of wear tracks reveal that delamination, plastic deformation and surface fracture are the dominant mechanisms during the wear process. Based on experimental observations in this study, several factors can be identified that affect the wear resistance of the water jet treated Al-Si alloys, namely, amount of porosity, pore size and shape and hardness of the subsurface region. The wear tracks of the samples were characterized by plastic deformation and damage in the form of plastic flow extending parallel to the sliding direction as shown in Figure 7(a). Surface pores act as stress concentration sites, the area around pores tend to fracture as a result of the stress exerted by the slider. This is evident from the cracks initiating from pore edge shown in Figure 7(b). Furthermore, Hertzian type cracks develop as a result of surface tensile stresses that evolve during Hertzian contact. These types of cracks normally extend perpendicular to the sliding direction. Figure 7(c) shows cracks perpendicular to the sliding direction which represents a clear evidence of Hertzian cracks developing during the wear process.

The other mechanism contributing to the observed wear is delamination. Initially, plastic deformation of surface layers due to cyclic normal and tangential loads take place, followed by crack or void nucleation in the deformed layers at pore sites (as pores act as stress concentration zones). Cracks nucleate at depth where shear stress is maximum as predicted by the Hertzian theory [35]. Then cracks grow nearly parallel to the surface and eventually become unstable and extend to the surface leading to the formation of thin, plate-like wear debris. Furthermore, the cracks extend and create a network of cracks by connecting different subsurface pores (Figure 7(d)). Pores serve as the origin and end of crack propagation, hence reducing the required length of crack propagation. This represents clear evidence that porosity in the subsurface layer accelerates delamination wear.

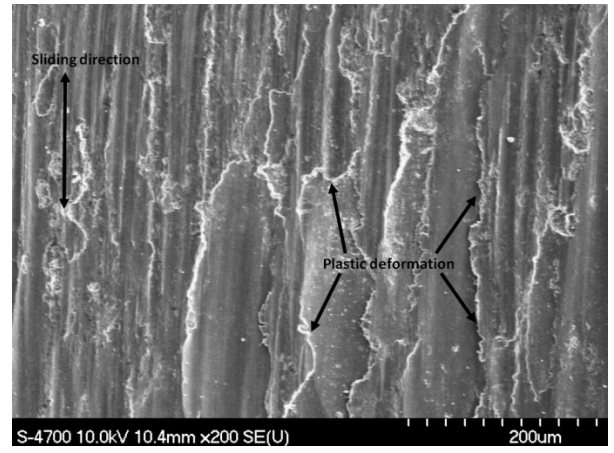

(a)

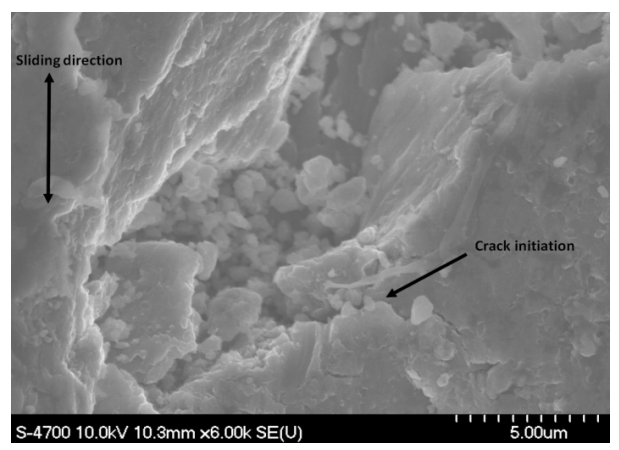

(b)

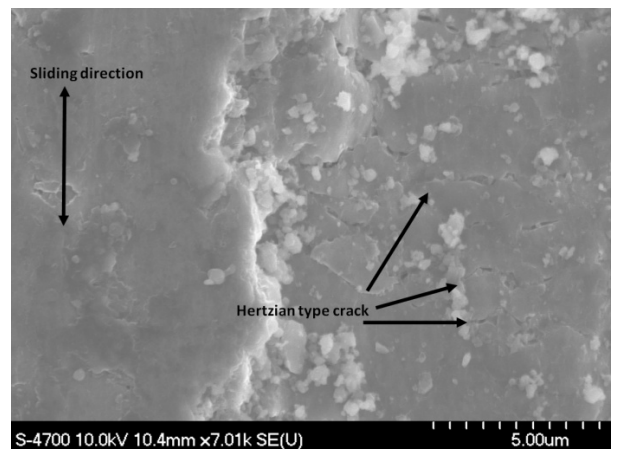

(c)

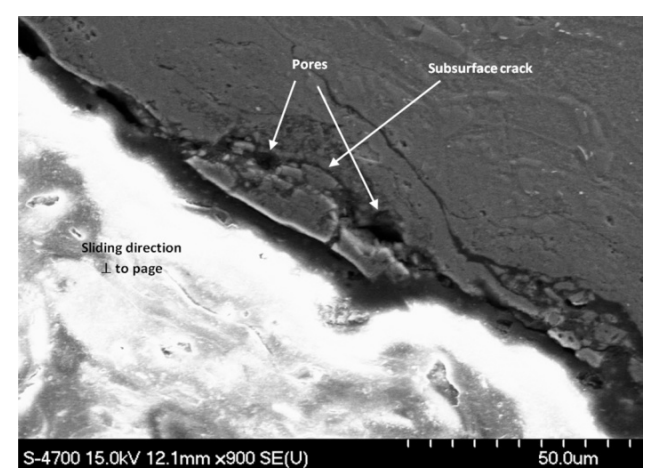

(d)

Figure 7. SEM observation of wear tracks. (a) plastic deformation, (b) crack nucleation from pore edge, (c) Hertzian crack perpendicular to the sliding direction, (d) cross section of wear track, pore connects in the sub surface region. 
Based on SEM examination and Hertzian analysis (discussed in details in a previous work [13]), as expected, wear increase as porosity increases. However, at a critical pore size, where the contact area between the slider and sample surface is in the same order of magnitude as pore size, wear drops as the counterface slides into the pore, hence, not contributing to wear loss.

\section{Conclusions}

In the present work, the potential of using high pressure water-jet as a surface treatment for Al-Si alloys to mitigate the effect of surface porosity was assessed and the following main conclusions have emerged.

a. The amount of subsurface porosity and average pore size drops after water jet treatment.

b. Subsurface work hardening and compressive residual microstrain develop as a result of water jet pressure.

c. Ploughing of grains, transgranular and intergranular propagation of cracks are the mechanisms for material removal during water jet treatment.

d. High pressure water-jet treatment is more effective than HIP in promoting superior wear resistance. Prolonged heating at high temperature during HIP decreases the total amount of porosity at the expanse of decreased hardness. While water jet produces hard compressed subsurface 'tribolayer' leading to increased wear resistance of the Al-Si alloy.

\section{Acknowledgements}

The author would like to thank Auto-21 for financial support, Bodycote International for performing HIP experiments and Vector Aerospace for performing water jet treatment.

\section{REFERENCES}

[1] S. A. Hofacker, "The Large Aircraft Robotic Paint Stripping System," Proc. $7^{\text {th }}$ American Water Jet Conference," Water Jet Technology Association, St Louis, 1993, pp. 613-628.

[2] M. Wen, L. Zhang, H. Han, Y. Dong, Z. Che, "WaterJet-Technology and Its Application for Preventing PumpCavitation," Renewable Energy Resources, Vol. 28, No. 2, 2010, pp. 145-147.

[3] B. Wood, "A Water-Cooled, Hydraulically Positioned 20,000 Psi Lance for Waterblasting Inside a Hot Klin," Jetting Technology, Mechanical Engineering Publication Limited, London, 1996, pp. 379-392.

[4] A. W. Momber and A. G. Nielsen, "Pipeline Rehabilitation by Water Jetting," Material Evaluation, Vol. 37, 1998, pp. 97-101.

[5] R. Yasui, A. Yanari and F. M. Carletti, "The Removal of
Excessive Resin from Semiconductor Leadframes with Spot-Shot Waterjets," Proceeding 7th American Water Jet Conference, Water Jet Technology Assoiation, St Louis, 1993, pp. 813-827.

[6] M. Raudensky, J. Horsky and L. Telecky, "Thermal and Mechanical Effect of High-Pressure Spraying of Hot Surfaces-Descaling," Proceeding 3rd International Metallurgic Conference, Continental Casting Dillets, Trinec, 1999, pp. 217-221.

[7] A. W. Momber and R. Kovacevic, "Principals of Abrasive Water Jet Machining." Springer-Verlag Ltd., London, 1998.

[8] G. Anirban, M. Ronald and R. Balachandar, "An Experimental and Numerical Study of Water Jet Cleaning Processes," Journal of Materials Processing Technology, Vol. 211, No. 4, 2011, pp. 610-618. doi:10.1016/j.jmatprotec.2010.11.017

[9] A. W. Momber, "Water Jet Applications in Construction Engineering," A A Balkema, Rotterdam, 1998.

[10] S. Srinivas and N. Ramesh, "An Analytical Model for Predicting Depth of Cut in Abrasive Water Jet Cutting of Ductile Materials Considering the Deflection of Jet in Lateral Direction," International Journal of Abrasive Technology Vol. 2, No. 3, 2009, pp. 259-278. doi:10.1504/IJAT.2009.024398

[11] H. Orbanic and M. Junkara, "Analysis of Striation Formation Mechanism in Abrasive Water Jet Cutting," Wear Vol. 265, No. 5-6, 2008, pp. 821-830. doi:10.1016/j.wear.2008.01.018

[12] H. Torabiana, J. P. Pathaka and S. N. Tiwaria, "Wear Characteristics of Al-Si Alloys," Wear, Vol. 172, 1994, pp. 49-58.

[13] M. Elmadagli, T. Perry and A. T. Alpas, "A Parametric Study of the Relationship between Microstructure and Wear Resistance of Al-Si Alloys," Wear, Vol. 262, No. 1-2, 2007, pp. 79-92. doi:10.1016/j.wear.2006.03.043

[14] N. Saka, A. M. Eleiche and N. P. Suh, "Wear of Metals at High Sliding Speeds," Wear, Vol. 44, No. 1, 1977, pp. 109-125. doi:10.1016/0043-1648(77)90089-8

[15] T. M. Chandrashekharaiah and S. A. Kori "Effect of Grain Refinement and Modification on the Dry Sliding Wear Behaviour of Eutectic Al-Si Alloys," Tribology International, Vol. 42, No. 1, 2009, pp. 59-65. doi:10.1016/j.triboint.2008.05.012

[16] S. Hegde and K. N. Prabhu, "Modification of Eutectic Silicon in Al-Si Alloys," Journal of Material Science, Vol. 43, 2008, pp. 3009-3027. doi:10.1007/s10853-008-2505-5

[17] G. F. Bocchini, "The Influence of Porosity on the Characteristics of Sintered Materials," International Journal of Powder Metallurgy, Vol. 22, No. 3, 1986, pp. 185-202.

[18] F. Akhlaghi and A. A. Zare-Bidaki, "Influence of Graphite Content on the Dry Sliding and Oil Impregnated Sliding Wear Behavior of Al 2024-Graphite Composites Produced by in Situ Powder Metallurgy Method," Wear, Vol. 266, No. 1-2, 2009, pp. 37-45. 
doi:10.1016/j.wear.2008.05.013

[19] H. Danninger, G. Jangg, B. Weiss and R. Stickler, "Microstructure and Mechanical Properties of Sintered Iron, Part I: Basic Considerations and Review of Literature," Powder Metallurgy International, Vol. 25, No. 3, 1993, pp. 111-117.

[20] M. A. Islam and Z. N. Farhat, "Effect of Porosity on Dry Sliding Wear of Al-Si Alloys," Tribology International, Vol. 44, No. 4, 2011, pp. 498-504. doi:10.1016/j.triboint.2010.12.007

[21] D. A. Gerard and D. A.Koss., "Low Cycle Fatigue Crack Initiation: Modeling the Effect of Porosity," International Journal of Powder Metallurgy, Vol. 26, No. 4, 1990, pp. 337-343.

[22] Y. Mai, B. Cotterell, S. Q. He and Y. B. Ke, "Handbook of Fatigue Crack Propagation in Metallic Structures," Amsterdam: Elsevier, Vol. 1, 1991, pp. 221-246.

[23] A. Shimamoto, R. Kubota and S. Yang, "Effects of Water Jet Peening and Hardening Treatment on Fatigue Properties of SCr420," ASME Conference Proceeding, Vol. 3, 2009, pp. 425-432.

[24] K. Hirano, K. Enomoto, M. Mochizuki, M. Hayashi, E. Hayashi and S. Shimizu, "Improvement of Residual Stress on Material Surface by Water Jet Peening," Translation of the $14^{\text {th }}$ International Conference on Structural Mechanicsin Reactor Technology, Lyon, France, 1997, pp. 17-22.

[25] B. Han and D. Y. Ju, "Compressive Residual Stress Induced by Water Cavitation Peening: A Finite Element Analyses," Materials \& Design, Vol. 30, No. 8, 2009, pp. 3325-3332. doi:10.1016/j.matdes.2008.11.029

[26] "Method for Determination of Density of Compacted or Sintered Powder Metallurgy Products-Standard 42," Standard Test Methods of Metal Powders and Powder Metallurgy Products, Metal Powder Industries Federation, New
Jersey, Princeton, 2002, pp. 59-61.

[27] "Standard Practice for Determining the Inclusion or Second-Phase Constituent Content of Metals by Automatic Image Analysis," Annual Book of ASTM Standards: E 1245-03.

[28] G. K. Williamson and W. H. Hall, "X-ray Line Broadeningfromjiled Aluminium and Wolfram," Acta Metallurgica, Vol. 1, No. 1, 1953, pp. 22-31. doi:10.1016/0001-6160(53)90006-6

[29] A. L. Patterson, "The Scherrer Formula for X-Ray Particle Size Determination," Physical Review, Vol. 56, No. 10, 1939, pp. 978-982. doi:10.1103/PhysRev.56.978

[30] "Standard Test Method for Knoop and Vickers Hardness of Materials," Annual book of ASTM Standards: E 384 $10^{€ 2}$

[31] S. P. Nikanorov, M. P. Volkov, V. N. Gurin, Y. A. Burenkov, L. I. Derkachenko, B. K. Kardashev, L. L. Regel and W. R. Wilcox, "Structural and Mechanical Properties of Al-Si Alloys Obtained by Fast Cooling of a Levitated Melt," Materials Science and Engineering A, Vol. 390, No. 1-2, 2005, pp. 63-69. doi:10.1016/j.msea.2004.07.037

[32] H. G. Jiang, M. Ruhle and E. J. Lavernia, "On the Applicability of the X-Ray Diffraction Line Profile Analysis in Extracting Grain Size and Microstrain in Nanocrystalline Materials," Journal of Materials Research, Vol. 14, No. 2, 1999 , pp. 549-559.

[33] G. K. Williamson and W. H. Hall, "X-ray Line Broadening from Filed Aluminium and Wolfram," Acta Metallurgica, Vol. 1, No. 1, 1953, pp. 22-31.

[34] M. A. Islam and Z. N. Farhat, "The Influence of Porosity and Hot Isostatic Pressure Treatment on Wear Characteristics of Cast and P/M Aluminum Alloys," Wear, 2011.

[35] K. Johnson, "Contact Mechanics," 1st Edition, Cambridge University Press, United Kingdom, 1987. 